\title{
Research on Construction Project Cost Control System based on Multivariate Optimization Theory
}

\author{
Xu Feng ${ }^{1}$ \\ ${ }^{1}$ Xi'an Siyuan University,Shaanxi, 710038 China
}

\begin{abstract}
In this paper, we research on the construction project cost control system based on multivariate optimization theory. With the development of economy, under the planned economy system construction enterprise according to the national plan for the construction of model no longer exists, the establishment of the modern enterprise management system, promote the market economic system gradually establish and perfect. We combine the multivariate method with traditional management systems. The numerical simulation proves the effectiveness of our approach. In the future, we will conduct more analysis and simulation to modify the propose method.
\end{abstract}

Keywords: Cost Control System; Multivariate Optimization; System Management; Multivariate.

\section{Introduction}

Construction enterprise project cost management, it is the use of technology in the general process of construction project planning and implementation, methods and management of expenses and resource cost plan, organization, coordination, supervision and remedy the check in time has happened and what will happen various deviation of a system engineering with its purpose is through a variety of cost management means have the most to gain from the smallest spending, in order to increase corporate profits, expanding the capital accumulation, to say the cost management is successful or not, a direct impact on corporate profits. With the development of economy, under the planned economy system construction enterprise according to the national plan for the construction of model no longer exists, the establishment of the modern enterprise management system, promote the market economic system gradually establish and perfect. Under the new economic system, construction companies operate independently, self-financing become the existence form, because the enterprise need to pay for themselves, in order to get the increase in economic benefit and profit space, enterprises must improve their own competitiveness [1-3]. It is the key to the construction enterprise project management, but the construction enterprise at present the study of enterprise cost management from the whole, did not establish effective responsibility, right and consistent management system, and mostly confined to the consumption of resources in the project construction cost control, and ignore the quality of the project cost, construction cost, safety and other epitaxial cost management. Nimble management, does not pay attention to the external environment in the process of resource supply change these caused the rise in the cost of engineering management problem, waste of resources, influence enterprise development, so the timely discovery and solve project cost management problems existing in the construction process, to ensure the quality of construction and engineering progress conditions, to reduce the engineering cost.

The principle of scientific, effective, can help in the construction process of cost management, cost management system constantly improve, can also help improving cost accounting information level. Strictly in accordance with the relevant provisions of the supervision system in 
construction cost management system design, the rules of the specific responsibilities to carry out the good, to the improvement of the division of duties, effectively control the construction cost. The whole process of cost control is divided into three stages: beforehand control, matter controls, afterwards controls. Three stages should be given priority to beforehand control, namely in project investment phase began which could get twice the result with half the effort effect [4].

The job involved has a very wide range of content, mainly including the external and internal cost control of construction engineering project cost control. From the microcosmic point of view, its means in the process of building engineering construction cost prediction, planning, analysis, calculation and decision-making work, scientific determine the goal of cost management and control, to ensure the smooth completion of the construction project. Quality cost means to ensure the quality of the project cost of all, it also include the cost that do not meet the quality standard, the process of engineering quality is bound to affect the cost control work, therefore, related personnel must correctly handle the relationship between quality and cost. The actual situation is, however, the majority of engineers in the building industry in our country hasn't realized the contradiction between both is attached great importance to the construction quality, but ignore the cost of construction project which produced a lot of unnecessary economic losses.

In this paper, we research on the construction project cost control system based on multivariate optimization theory. Construction project cost control is a dynamic and complex system and the construction project investment control in the range of scientific and reasonable, to ensure to achieve the goals of project investment, made in the each stage of project construction on the rational use of manpower, material resources, financial resources, to ensure the investment benefit and social benefit of enterprise and therefore, should be according to the characteristics of the project itself and establish the cost management system and the specific operation method, such application in the process of implementing a variety of reasonable cost control methods which achieve the goal of effective cost control. In the figure one, we show the general elements and components for cost management. In the following sections, we will discuss the proposed methodology in detail.

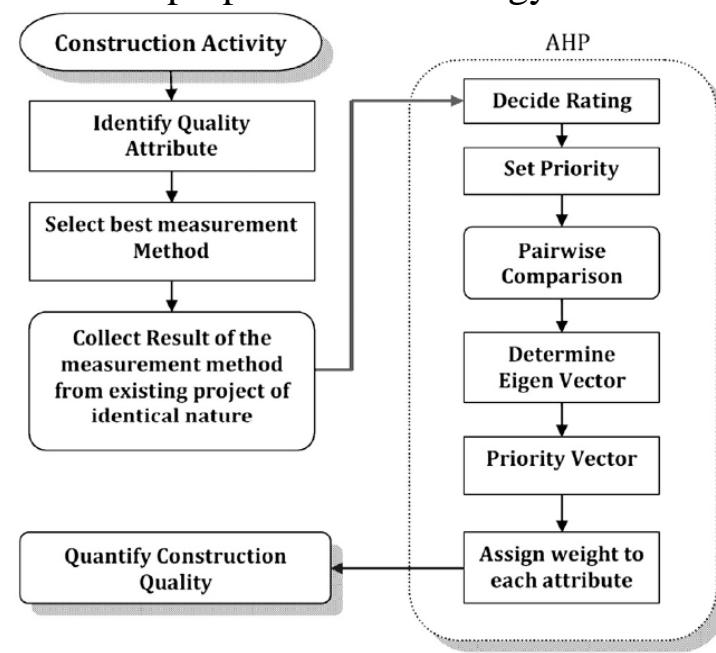

Fig. 1The General Elements for Cost Management to Analysis

\section{The Proposed Methodology}

The Principles of Project Cost Management. Project cost control is throughout the entire process of construction engineering project, but we should control the focus of the find, project cost control is the key project construction before the decision phase and design phase, and the key to control the project cost is the design phase. The design of the project for the cost of engineering play a crucial role, a design phase of the project investment effect can reach more than $75 \%$. For a long time, we ignore the prophase of the project is the project cost control, cost control of the main application in the construction stage and completion inspection and acceptance stage. It can also control the cost of the project, but we didn't catch the key link. To effectively control construction project cost of the project, you must take the combination of technical and economic 
means to control project cost, we should take measures from the technology, economy and so on. From the aspects of technology, we should strengthen the choice of design ability and strictly check the design scheme, selection of an optimal design scheme. For design of preliminary design, technical design and construction drawing design, the design of the construction organization design and use of materials should be comparison, find the economic and reasonable design scheme. Economically, take effective measures to control the cost of spending for the design scheme for saving investment reward, so that we can make the design more economic and reasonable. Quality and cost between the opposition and the dialectical relations of the same. As a general rule, the higher the required quality level, the resources needed to complete the project in the cycle and the higher the human, caused the higher the cost of implementation.

Construction engineering cost management involves all aspects of the construction of the project, not only contains the whole process of cost management, that is, from parts completion settlement cost prediction to the enterprise, should avoid general enterprise attaches great importance to the construction process control, ignore costs beforehand and afterwards control of bad practices also include total cost management, that is, cost management is not only the work of cost management, all participants must have the consciousness of cost control. To conduct a comprehensive cost control, in particular, attaches great importance to the project before the construction cost control, including material cost control is the core of cost control of control project, because the cost of materials for a large proportion in the engineering cost, directly affects project cost and economic benefits, so to achieve all-round, the whole process of management.

The Multivariate Optimization Theory based Methodology. At present, most of the construction enterprise has not yet form the scientific system of target cost, cost management is still limited to a narrow resource cost reduction, cost management goals. For example, many constructions projects only cost control was carried out on the cost of raw materials, labor and other routine expenses, but ignore the quality of the project cost, time cost, safety cost and other epitaxial cost management. For construction project cost management goal is to make the total cost to a minimum. The increase of the quality cost caused by insufficient quality or quality excess, quality deficiency can lead to rework, increase the cost, the increased cost of quality will directly cause excess. At the same time, more can't ignore the quality and safety costs in order to save time cost and finally result in an increase in the total cost. The ultimate goal of the project cost management is to minimize the total cost. Project cost and the quality of the product level exist interdependence, if constantly in order to reduce costs and shoddy, reduce the engineering quality, rework repair, as well as the quality problems will happen increase the cost. So they should be on the basis of engineering contract, at the same time, according to the company's business strategy, determine reasonable quality targets, do plan contract within a reasonable time limit for a project to meet quality requirements, which can maximize the setting up enterprise brand, enlargement popularity, follow-up management provides resources for the enterprise. Security incidents will not only bring obvious Roman loss, also affect the site construction, lead to the construction progress and various aspects so as to general increase the construction cost. The formulas show the optimization methodology.

$$
C_{k}(P)=\sum_{k=1}^{m} a_{k} C_{k}(P)
$$

Equality constraint solving quadratic programming problems which are essentially to solve its stable point though laser function, that is, to solve the following system of linear equations.

$$
\Delta B+\Delta^{2} B d-A^{t} \lambda=0
$$


Evidence theory is the result of the support degree of each target, rather than the probability, it support the biggest goal as recognition results. Convex optimization method is the result of the probability distribution of the target and it is the highest probability of target as the recognition result.

$$
\bar{u}(t) \in U(t), \bar{v}(t) \in V(t)
$$

Construction engineering cost management in foreign countries has become a systematic and integrated knowledge system. A project in the process of implementation, mainly about the quality of the project, effectively control the cost and time, and adopt corresponding methods of mathematical analysis, value engineering, value analysis, technical economics tools or techniques such as analysis of project management knowledge areas, processing and control, to make it along the prior degrees determine the goal and direction. For management activities, has only adhere to the consistent management system, in order to obtain maximum management effect and cost management is no exception. In the process of project cost control and management of the enterprise must give the project manager and other management personnel in a certain power.

The Numerical Analysis for the Proposed Method. On cost management consciousness, the construction enterprise from the cost analysis of budget, accounting and personnel cost control aspects of education, to implement the cost budget management. After elaboration to each department, technical department to make the technical measures in advance. The finance department to assist traffic tools and project management personnel equipped with conditions as the basis. Cost budget is not only related to enterprise managers, as one of the ways to improve enterprise economic benefits, it has to do with every employee has the close relationship, so you should according to the actual situation, in setting out the consumption of the lowest cost plan, strengthen the staff cost control consciousness, to mobilize all positive forces. In the following figure two, we show the management numerical simulation statistical result.

\begin{tabular}{|c|c|c|c|c|c|c|c|c|c|c|c|c|c|c|c|}
\hline \multirow{2}{*}{ Type } & \multirow{2}{*}{$\begin{array}{l}\text { \% of Cost } \\
\text { Invested }\end{array}$} & \multicolumn{2}{|c|}{ Response } & \multirow{2}{*}{ Mean } & \multirow{2}{*}{ SD } & \multirow{2}{*}{$\begin{array}{l}\text { \% of Time } \\
\text { Invested }\end{array}$} & \multicolumn{2}{|c|}{ Response } & \multirow{2}{*}{ Mean } & \multirow{2}{*}{ SD } & \multirow{2}{*}{$\begin{array}{l}\text { \% of Labor } \\
\text { Invested }\end{array}$} & \multicolumn{2}{|c|}{ Response } & \multirow{2}{*}{ Mean } & \multirow{2}{*}{ SD } \\
\hline & & $\mathrm{N}$ & $\%$ & & & & $\mathrm{~N}$ & $\%$ & & & & $\mathrm{~N}$ & $\%$ & & \\
\hline \multirow{5}{*}{$\begin{array}{c}\text { Contractual Risk } \\
(\mathrm{N}=36)\end{array}$} & $1 \%$ & 3 & $9 \%$ & \multirow{5}{*}{$3.8 \%$} & \multirow{5}{*}{$1.1 \%$} & $2 \%$ & 3 & $8 \%$ & \multirow{5}{*}{$3.1 \%$} & \multirow{5}{*}{$1.3 \%$} & $2 \%$ & 2 & $6 \%$ & \multirow{5}{*}{$4.2 \%$} & \multirow{5}{*}{$1.1 \%$} \\
\hline & $2 \%$ & 12 & $33 \%$ & & & $3 \%$ & 18 & $50 \%$ & & & $3 \%$ & 9 & $25 \%$ & & \\
\hline & $3 \%$ & 8 & $22 \%$ & & & $4 \%$ & 1 & $3 \%$ & & & $4 \%$ & 9 & $25 \%$ & & \\
\hline & $4 \%$ & 4 & $11 \%$ & & & $5 \%$ & 13 & $36 \%$ & & & $5 \%$ & 13 & $36 \%$ & & \\
\hline & $5 \%$ & 9 & $25 \%$ & & & $6 \%$ & 1 & $3 \%$ & & & $6 \%$ & 3 & $8 \%$ & & \\
\hline \multirow{6}{*}{$\begin{array}{l}\text { Procurement Risk } \\
(\mathrm{N}=30)\end{array}$} & $1 \%$ & 9 & $30 \%$ & \multirow{4}{*}{$2.2 \%$} & \multirow{4}{*}{$1.0 \%$} & $1 \%$ & 2 & $7 \%$ & \multirow{5}{*}{$3.4 \%$} & \multirow{5}{*}{$1.3 \%$} & $1 \%$ & 4 & $13 \%$ & \multirow{6}{*}{$3.0 \%$} & \multirow{6}{*}{$1.3 \%$} \\
\hline & $2 \%$ & 9 & $30 \%$ & & & $2 \%$ & 6 & $20 \%$ & & & $2 \%$ & 7 & $23 \%$ & & \\
\hline & $3 \%$ & 9 & $30 \%$ & & & $3 \%$ & 9 & $30 \%$ & & & $3 \%$ & 8 & $27 \%$ & & \\
\hline & $4 \%$ & 3 & $10 \%$ & & & $4 \%$ & 5 & $17 \%$ & & & $4 \%$ & 7 & $23 \%$ & & \\
\hline & - & - & - & - & - & $5 \%$ & 8 & $26 \%$ & & & $5 \%$ & 3 & $10 \%$ & & \\
\hline & - & - & - & - & - & - & - & - & - & - & $6 \%$ & 1 & $4 \%$ & & \\
\hline \multirow{6}{*}{$\begin{array}{l}\text { Safety and Health } \\
\text { Risk }(\mathrm{N}=30)\end{array}$} & $1 \%$ & 9 & $30 \%$ & \multirow{3}{*}{$2.1 \%$} & \multirow{3}{*}{$0.8 \%$} & $1 \%$ & 11 & $37 \%$ & & & $1 \%$ & 4 & $13 \%$ & \multirow{6}{*}{$2.7 \%$} & \multirow{6}{*}{$1.2 \%$} \\
\hline & $2 \%$ & 9 & $30 \%$ & & & $2 \%$ & 15 & $50 \%$ & $1.8 \%$ & $0.7 \%$ & $2 \%$ & 11 & $37 \%$ & & \\
\hline & $3 \%$ & 12 & $40 \%$ & & & $3 \%$ & 4 & $13 \%$ & & & $3 \%$ & 10 & $33 \%$ & & \\
\hline & - & - & - & - & - & - & - & - & - & - & $4 \%$ & 2 & $7 \%$ & & \\
\hline & - & - & - & - & - & - & - & - & - & - & $5 \%$ & 2 & $7 \%$ & & \\
\hline & - & - & - & - & - & - & - & - & - & - & $6 \%$ & 1 & $3 \%$ & & \\
\hline
\end{tabular}

Fig. 2The Numerical Statistical Result for the Proposed Method

\section{CONCLUSIONS}

In this paper, we research on the construction project cost control system based on multivariate optimization theory. In the construction project construction process, according to the actual situation of the scene, the, standardization and standardized as follows the principle of 
democratic centralism, and the rights and responsibilities, the running mechanism of the trinity and the management pattern to restrict the behavior of the departments and their staff. At present, the construction enterprise project construction process of effective management mode is the organization intends to, in this mode, the cost of the project management shall be the responsibility of the project intends to, and the body of the project cost management is the management and construction personnel. Our proposed optimization methodology will enhance the performance of the projects.

\section{References}

[1] Chang-Ming H U, Dong X, Liu K. Linear materials cost control of construction project based on grey prediction and multi-objective genetic algorithm[J]. Journal of Guangxi University, 2014.

[2] Li, S. (2014). Identification for key risk sub-factors of project cost control in construction enterprises. Construction Technology.

[3] Zhang, Y., \& Zhuang, S. Y. (2014). Study on the cost control of construction project. Applied Mechanics \& Materials, 638-640.

[4] Yan, W. Z., \& Chen, P. (2014). Based on the system dynamics construction phase of the project cost control study. Advances in Civil \& Structural Engineering III, 501-504. 